\title{
PENGARUH WEBSITE QUALITY, WEBSITE REPUTATION DAN PERCEIVED RISK TERHADAP PURCHASE INTENTION PADA PERUSAHAHAAN E-COMMERCE
}

\author{
Harry Jundrio ${ }^{1}$, Keni Keni \\ ${ }^{1}$ Program Magister Manajemen, Universitas Tarumanagara Jakarta \\ Email:harry.jundrio@gmail.com \\ ${ }^{2}$ Program Magister Manajemen, Universitas Tarumanagara Jakarta \\ Email:keni@fe.untar.ac.id
}

\begin{abstract}
ABSTRAK
Tujuan penelitian ini adalah untuk menguji secara empiris pengaruh kualitas website, reputasi website dan persepsi risiko terhadap minat beli dari pengunjung website atau aplikasi e-commerce. Penelitian ini menggunakan metode sampling non probability dengan teknik convenience sampling. Sampel berjumlah 203 responden yang mayoritas adalah karyawan BUMN, PNS atau swasta. Partial Least Squares - Structural Equation Model (PLS - SEM) digunakan untuk melakukan analisis data dengan menggunakan softwate Smart PLS 3.3.0. Hasil penelitian ini menunjukan bahwa perusahaan telah memiliki kualitas website dan reputasi website yang baik, sehingga kualitas website dan reputasi website memiliki pengaruh positif terhadap minat beli. Hasil penelitian ini juga menunjukkan bahwa perusahaan dipersepsikan sebagai website/aplikasi dengan risiko netral, sehingga persepsi risiko tidak memiliki pengaruh terhadap minat beli. Penelitian ini menyarankan agar perusahaan mempertahankan dan meningkatkan kualitas website dan reputasi website untuk meningkatkan minat beli pengunjung. Dan dikarenakan perusahaan adalah platform e-commerce yang bekerja sama dengan penjual dan kurir pihak ketiga, maka perusahaan agar menetapkan peraturan yang tegas untuk menjamin potensi risiko yang minimal pada saat transaksi.
\end{abstract}

Kata Kunci: kualitas website, reputasi website, persepsi risiko, minat beli, e-commerce

\begin{abstract}
The purpose of this research is to investigate the effects of website quality, website reputation and perceived risk on purchase intention towards visitors of e-commerce website or application. This research uses non probability sampling method with convenience sampling technique. The sample number is 203 respondents which mostly are state-owned, public or private sector employees. Partial Least Squares - Structural Equation Modeling (PLS SEM) is used to analyze research data by using Smart PLS 3.3.0 software. The findings show the company already has good website quality and good website reputation and therefore website quality and website reputation have positive effects on purchase intention. The findings also show that the websitelapplication is perceived as non risky website/application and therefore perceived risk has no effect on purchase intention. The findings suggest that the company should maintain and enhance its website quality and website reputation in order to increase visitors' purchase intention. And since the company is an e-commerce platform that has agreements with third-party sellers and courier services, it has to establish rigid standard operating procedures to ensure the minimalization of potential risk during transactions.
\end{abstract}

Keywords: webstite quality, website reputation, perceived risk, purchase intention, e-commerce

\section{PENDAHULUAN}

\section{Latar Belakang}

Konsumen tidak perlu lagi keluar rumah untuk berbelanja barang-barang yang dibutuhkan. Hanya dengan menggunakan ponsel yang terhubung dengan internet, konsumen dapat memilih barang-barang yang dibutuhkan pada website penjual ataupun pada website e-commerce dan kemudian kurir akan mengirimkannya langsung ke alamat yang dituju. Berbelanja online menjadi salah satu aktivitas yang menarik karena memberikan pengalaman baru dalam berbelanja bagi konsumen. Ini merupakan salah satu alasan konsumen mulai beralih dari sebelumnya harus ke pasar untuk membeli suatu barang (offline) menjadi secara digital dengan hanya mengunjungi situs belanja (Kata Data, 2018). Selain itu, alasan konsumen tertarik untuk 
berbelanja secara digital melalui platform e-commerce adalah karena mudah, tepat waktu, efisien dan dapat memangkas biaya dalam melakukan transaksi (Wilson, Keni \& Tan, 2019).

Pergeseran kebiasaan konsumen dari belanja offline menjadi belanja online ini terjadi karena perkembangan dunia industri yang dikenal dengan Revolusi Industri 4.0 yang melahirkan ekonomi digital. Ekonomi digital terdiri dari e-commerce, app stores, iklan secara online, layanan pembayaran online, cloud computing, participative networked platforms, dan lain-lain (Nuraini, 2018). Pertumbuhan ekonomi digital Indonesia telah mencapai US\$ 27 milyar pada tahun 2018 dan diprediksi akan tumbuh mencapai US\$100 milyar pada tahun 2025 (Google Temasek, 2018). E-commerce menurut Nuraini (2018) adalah penjualan atau pembelian barang dan jasa yang dilaksanakan melalui jaringan komputer dengan metode yang secara khusus didesain dengan tujuan untuk menerima atau melakukan permintaan. Barang dan jasa tersebut diminta dengan menggunakan metode yang didesain khusus tersebut, namun pembayaran dan pengirimannya tidak harus dilakukan secara online. Lee, Khong dan Hong (2014) menyebutkan bahwa e-commerce bermula pada akhir tahun 1990-an dan semakin meningkat popularitasnya pada awal tahun 2000-an. Sejak diperkenalkan kepada publik, e-commerce mewakili pergeseran paradigma yang secara radikal mengubah cara tradisional dalam menjalankan bisnis.

Beberapa faktor yang mendorong peningkatan industri e-commerce di Indonesia adalah peningkatan penetrasi smartphone dan internet, investasi asing yang intensif pada platform terdepan, pertumbuhan kelas menengah di Indonesia dan perbaikan yang baru-baru ini dilakukan terhadap sistem pembayaran online di Indonesia (Australian Trade and Investment Commission, 2018). Indonesia merupakan pemimpin di pasar Asia Tenggara dalam bisnis e-commerce. Pertumbuhan bisnis e-commerce di Indonesia mencapai US\$ 12 milyar pada tahun 2018 (Google Temasek, 2018). Lembaga riset Hootsuite merilis informasi bahwa jumlah masyarakat Indonesia yang belanja barang konsumsi lewat e-commerce sudah mencapai 107 juta pada Januari 2019. Angka ini setara dengan 40\% total penduduk Indonesia (CNBC Indonesia, 2019).

Tingginya pertumbuhan e-commerce di Indonesia ini salah satunya didukung oleh kemudahan konsumen mendapatkan akses informasi tentang produk yang akan dibelinya. Informasi tersebut digunakan oleh konsumen untuk melakukan evaluasi produk yang akan dibelinya tersebut. Hal ini sesuai dengan pendapat Athapaththu dan Kulathunga (2018) bahwa dalam melakukan evaluasi produk, konsumen menggunakan pengetahuan, pengalaman dan informasi eksternal. Pada saat inilah proses purchase intention dimulai. Pendapat tersebut juga sejalan dengan pendapat Kotler dan Armstrong (2012) bahwa purchase intention akan muncul setelah seorang calon konsumen melakukan evaluasi terhadap suatu produk atau jasa. Purchase intention menjadi penting untuk diteliti karena tahap inilah yang menentukan jadi atau tidaknya seorang konsumen membuat keputusan untuk membeli produk yang diminatinya. Perusahaan yang mengetahui faktor-faktor yang mempengaruhi purchase intention dapat membantu perusahaan dalam memenuhi keinginan konsumen (Sari dan Keni, 2019) dan memperkuat hubungan perusahaan dengan konsumen sehingga saling menguntungkan (Mirabi, Akbariyeh dan Tahmasebifard, 2015). Dalam konteks e-commerce, perusahaan perlu mengetahui faktor-faktor apa saja yang mempengaruhi minat beli seorang konsumen ketika mengunjungi website $e$ commerce tersebut. Perusahaan e-commerce yang memberikan perhatian lebih pada faktor-faktor yang mempengaruhi minat beli konsumen pada website-nya akan dapat meningkatkan minat beli konsumen (Wu et al., 2014). 
Terdapat beberapa faktor yang mempengaruhi purchase intention. Menurut Lee, Khong dan Hong (2014), purchase intention dipengaruhi oleh shopping enjoyment dan consumer trust. Sementara menurut Weisberg, Te'eni dan Arman (2011), purchase intention dipengaruhi oleh past purchasing experience. Lebih lanjut menurut Kwahk, Ge dan Park (2012), purchase intention dipengaruhi oleh instant messaging. Adapun menurut Athapaththu dan Kulathunga (2018), purchase intention dipengaruhi oleh perceived usefulness, perceived ease of use, website content dan social commerce construct. Lebih lanjut menurut Bonera (2011), facilitating conditions, perceived self efficacy, experience, perceived usefulness, perceived ease of use, subjective norms, playfulness dan e-trust dapat menjelaskan purchase intention. Faktor selanjutnya yang mempengaruhi purchase intention menurut $\mathrm{Wu}$ et al. (2014) adalah layout design, atmosphere, emotional arousal dan attitude toward the website.

Salah satu faktor yang mempengaruhi purchase intention adalah website quality. Website quality adalah persepsi konsumen secara keseluruhan tentang fungsi dan penampilan sebuah website (Lowry et al., 2008). Website dengan desain yang baik dan konten yang mudah diakses akan meningkatkan niat beli dari konsumen yang mengunjungi website tersebut (Law \& Bai, 2008). Selain website quality, purchase intention juga dipengaruhi oleh website reputation. Website reputation adalah persepsi positif konsumen terhadap sebuah website yang dihasilkan dari pengalaman konsumen dalam menggunakan website tersebut (Tangmanee \& Rawsena, 2016). Website dengan reputasi yang baik akan mendorong konsumen untuk berbelanja pada website tersebut (Tangmanee \& Rawsena, 2016; Kim \& Lennon, 2013). Purchase intention juga dipengaruhi oleh persepsi risiko konsumen terhadap website yang dikunjunginya. Perceived risk adalah persepsi konsumen terhadap ketidakpastian ketika bertransaksi pada sebuah website (Tangmanee \& Rawsena, 2016). Semakin tinggi risiko sebuah website yang dipersepsikan oleh konsumen, maka akan semakin rendah niat beli konsumen pada website tersebut (Li, Kim \& Park, 2007).

Penelitian ini bertujuan untuk menguji secara empiris pengaruh website quality, website reputation dan perceived risk terhadap purchase intention pada perusahaan e-commerce. Hasil penelitian ini diharapkan dapat berkontribusi untuk mendapatkan gambaran tentang consumer behavior dalam berbelanja online dan untuk mendapatkan informasi tentang bagaimana meningkatkan website quality dan website reputation serta meminimalisasi perceived risk sehingga dapat meningkatkan purchase intention konsumen.

\section{Telaah Kepustaaan \\ Purchase intention}

Purchase intention menurut Ganguly et al. (2010: 307) adalah "purchase intention is concerned with the likelihood to purchase products online." Sementara itu Wu et al. (2014: 11) mendefinisikan purchase intention sebagai "purchase intention was measured by the probability or likelihood that people would engage in specific purchasing behaviour." Selanjutnya Athapaththu dan Kulathunga (2018: 114) menyebutkan definisi purchase intention sebagai "purchase intention of the online shopper is the final stage, after various prompts of the online shopper." Niat konsumen untuk berbelanja pada sebuah website menjadi prediktor yang penting untuk menentukan apakah konsumen tersebut akan melakukan keputusan pembelian atau tidak. Berdasarkan definisi-definisi di atas, dapat disimpulkan bahwa purchase intention adalah kemungkinan seorang konsumen melakukan pembelian sebuah produk atau jasa. 


\section{Website quality}

Lowry et al. (2008: 205) mendefinisikan website quality sebagai "consumers' overall perceptions of how well they think a website works and looks." Sementara Lu dan Yeung (1998: 8) mendefinisikan website quality sebagai "the quality and usefulness of a website comprise functionality and usability." Lebih lanjut Hsu, Chang dan Chen (2012: 551) mendefinisikan website quality sebagai "the quality of a website can be addressed in terms of system quality, information quality and service quality." Desain website yang menarik dan mudah untuk dinavigasikan akan memberikan pengalaman yang positif kepada konsumen yang pada akhirnya akan dapat mendorong konsumen untuk berbelanja pada website tersebut. Berdasarkan definisidefinisi di atas, dapat disimpulkan bahwa website quality adalah desain sebuah website dan bagaimana kontennya disusun sedemikian rupa sehingga memudahkan konsumen dalam menggunakan dan memanfaatkan website tersebut.

\section{Website reputation}

Definisi website reputation menurut Tangmanee and Rawsena (2016: 3) adalah 'customers' positive perception of the website as a result of their exposure to the details in it or their prior experience associated with the website." Sementara definisi website reputation menurut van der Heijden, Verhagen dan Creemers (2003: 43) adalah "reputation is closely related to familiarity with the store." Lebih lanjut Jarvenpaa dan Tractinsky (1999: 5) mendefinisikan website reputation sebagai "provides assurances of the other party's ability, integrity and goodwill." Konsumen yang memiliki pengalaman yang positif terhadap sebuah website akan memiliki persepsi yang positif pula terhadap website tersebut. Persepsi yang positif ini akan membuat konsumen kembali mengunjungi website tersebut di kemudian hari dan melakukan pembelian. Berdasarkan definisi-definisi di atas, dapat disimpulkan bahwa website reputation adalah persepsi positif konsumen terhadap kemampuan, integritas, familiarity dan goodwill dari sebuah website.

\section{Perceived risk}

Definisi perceived risk menurut Dowling dan Staelin (1994: 119) adalah "consumer's perception of the uncertainty and adverse onsequences of buying a product a product or service." Sementara itu Li, Kim dan Park (2007: 273) mendefinisikan perceived risk sebagai "consumer's perceived wariness about possible leakage of credit card related information, perceived lack of feeling secure about protection of personal information and perceived wariness about possibility of no-refund or no return after ordering." Sedangkan Tangmanee and Rawsena (2016: 3) mendefinisikan perceived risk sebagai "customer's perception of uncertainty in the transaction through websites or in the outcome of the transaction." Kegagalan transaksi atau ketidaksesuaian produk yang diterima dengan yang diinformasikan pada website akan memberikan pengalaman berbelanja yang negatif kepada konsumen. Hal ini akan membuat konsumen merasa khawatir untuk berbelanja pada website tersebut. Pada kondisi yang ekstrim, konsumen dapat saja mengurungkan niatnya untuk berbelanja pada website tersebut. Berdasarkan defisinisi-definisi di atas, dapat disimpulkan bahwa perceived risk adalah persepsi kekhawatiran konsumen tentang ketidakpastian transaksi dan ketidaksesuaian produk yang dibeli serta kebocoran informasi pribadi dan layanan purna jual yang buruk.

\section{Kaitan antara Website quality dengan Purchase intention}

Hasil penelitian Kim dan Lennon (2013) menunjukkan bahwa website quality yang terdiri dari empat dimensi, yaitu website design, customer service, fulfillment/reliability dan security/privacy, berpengaruh signifikan positif terhadap purchase intention. Sementara itu hasil penelitian Law dan Bai (2008) juga menunjukkan bahwa website quality yang diukur dengan 
functionality factors dan usability factors, berpengaruh positif terhadap purchase intention. Selanjutnya hasil penelitian Hsu, Chang dan Chen (2012) juga menunjukkan bahwa tiga dimensi dari website quality, yaitu information quality, system quality dan service quality, memiliki hubungan yang positif dengan purchase intention. Website yang didesain dengan baik dan menampilkan informasi yang menyeluruh serta dengan sistem yang andal dan dapat berfungsi dengan baik akan meningkatkan keinginan konsumen untuk berbelanja pada website tersebut. Berdasaran uraian di atas, hipotesis penelitian adalah:

$\mathrm{H}_{1}$ : Website quality berpengaruh positif terhadap purchase intention.

\section{Kaitan antara Website reputation dengan Purchase intention}

Hasil penelitian penelitian Tangmanee dan Rawsena (2016) menunjukkan bahwa website reputation memiliki hubungan yang signifikan terhadap purchase intention. Hasil penelitian ini juga didukung oleh penelitian lain yang dilakukan oleh Kim dan Lennon (2013) yang mengklaim bahwa website reputation memiliki pengaruh signifikan positif terhadap purchase intention. Hal serupa juga ditemukan pada hasil penelitian Kim, Kim dan Yang (2013) bahwa hubungan website reputation dengan purchase intention adalah signifikan positif. Secara umum, website dengan reputasi yang baik dan dikenal baik oleh konsumen akan menampilkan citra yang baik pula yang pada akhirnya akan meningkatkan minat konsumen untuk berbelanja pada website tersebut. Berdasaran uraian di atas, hipotesis penelitian adalah:

$\mathrm{H}_{2}$ : Website reputation berpengaruh positif terhadap purchase intention.

\section{Kaitan antara Perceived risk dengan Purchase intention}

Tangmanee dan Rawsena (2016) dalam penelitiannya mengklaim bahwa perceived risk memiliki hubungan yang signifikan negatif terhadap purchase intention. Sementara itu Li, Kim dan Park (2007) dalam penelitiannya juga mengklaim bahwa perceived risk memiliki hubungan yang signifikan negatif terhadap purchase intention. Hasil yang sama juga ditemukan dalam penelitian Ariffin, Mohan dan Goh (2018) yang membagi perceived risk menjadi enam dimensi, yaitu financial risk, product risk, security risk, time risk, social risk dan psychological risk, bahwa perceived risk memiliki hubungan yang negatif terhadap purchase intention. Semakin tinggi konsumen mempersepsikan risiko dalam berbelanja pada sebuah website, maka akan semakin rendah minat konsumen untuk berbelanja pada website tersebut. Berdasaran uraian di atas, hipotesis penelitian adalah:

$\mathrm{H}_{3}$ : Perceived risk berpengaruh negatif terhadap purchase intention.

Berdasarkan uraian kaitan antar variabel di atas, maka model penelitian yang digunakan dapat digambarkan sebagai berikut:

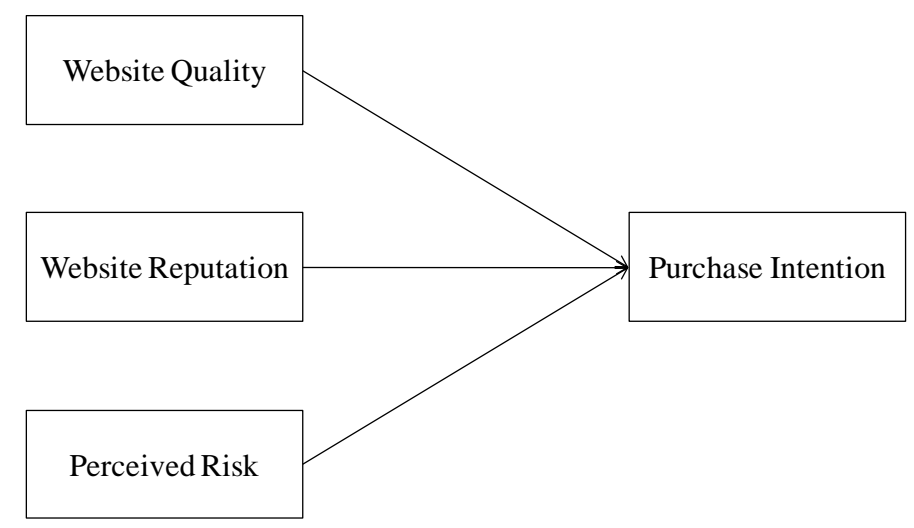

Gambar 1. Model Penelitian 


\section{METODE PENELITIAN}

Jenis penelitian ini adalah penelitian deskriptif cross-sectional yang dilaksanakan pada periode Mei 2019 hingga April 2020. Sampel penelitian ini adalah pengunjung website/aplikasi $e$ commerce yang dipilih dengan menggunakan teknik convenience sampling. Kuesioner disebarkan secara online menggunakan Google form dengan kriteria responden yang telah pernah mengunjungi website e-commerce atau aplikasi e-commerce pada smartphone. Total kuesioner yang berhasil dikumpulkan sebanyak 231 responden, namun yang dapat digunakan sebanyak 203 responden. Terdapat 28 responden yang tidak eligible karena belum pernah mengunjungi website/aplikasi e-commerce. Hasil pengolahan data kuesioner menunjukkan bahwa karakteristik mayoritas responden adalah responden laki-laki $(52,4 \%)$ dengan rentang umur antara 25-35 tahun (54,7\%) dengan pendidikan terakhir adalah S1 atau sederajat $(78,3 \%)$ dan bekerja sebagai karyawan swasta atau pegawai negeri sipil atau pegawai BUMN dan BUMD (90,6\%). Mayoritas responden memiliki penghasilan antara $\mathrm{Rp} 5$ hingga Rp 10 juta (42,9\%). Sebagian besar dari responden penelitian ini berbelanja online sebanyak satu kali dalam sebulan (45,8\%) dengan estimasi nilai belanja sebesar Rp 100 ribu hingga $\mathrm{Rp} 250$ ribu (35\%). Sedangkan jenis transaksi yang paling sering dilakukan oleh responden penelitian ini adalah transaksi belanja $(74,2 \%)$.

\begin{tabular}{ccc}
\multicolumn{2}{c}{ Tabel 1. Indikator Pengukuran Variabel } \\
Variabel & Item & Sumber \\
\hline Purchase intention & 4 item & Kim dan Lennon (2013); Ganguly et al. (2010); Wu et al. (2013) \\
\hline Website quality & 6 item & Kim dan Lennon (2013); Lowry et al. (2008) \\
\hline Website reputation & 4 item & Kim dan Lennon (2013); Li, Kim dan Park (2007) \\
\hline Perceived risk & 5 item & Ariffin, Mohan dan Goh (2018); Ganguly et al. (2010); Li, Kim dan Park
\end{tabular}
(2007)

Indikator-indikator dari variabel penelitian ini diukur dengan menggunakan skala Likert 1 sampai 5, di mana 1 sebagai angka paling rendah (sangat tidak setuju) dan 5 sebagai angka paling tinggi (sangat setuju). Berdasarkan hasil analisis model pengukuran (outer model analysis), ditemukan bahwa semua indikator yang digunakan untuk mengukur variabel-variabel penelitian bersifat valid dan reliabel sehingga dapat merepresentasikan variabel-variabel penelitian dan dapat dipercaya serta diandalkan. Hasil analisis validitas konvergen, yaitu nilai AVE $\geq 0,50$ dan factor loading > 0,70 (Hair Jr et al., 2014) dan validitas diskriminan, yaitu kriteria Fornell-Larcker dan nilai cross loading (Hair Jr et al., 2014) serta nilai composite reliability, yaitu > 0,6 dan nilai Cronbach Alpha, yaitu > 0,6 (Kuncoro, 2013) menunjukkan bahwa semua indikator penelitian telah memenuhi nilai syarat minimum dari metode pengukuran yang digunakan.

\section{HASIL DAN PEMBAHASAN}

Pengujian nilai path coefficient dilakukan untuk mengetahui bagaimana keterkaitan atau pengaruh antara variabel yang satu dengan variabel lainnya dalam sebuah penelitian. Hasil pengujian bootstrapping disajikan pada tabel berikut:

\begin{tabular}{|c|c|c|c|c|}
\hline Hipotesis & Variabel & Path Coefficient & $t$-statistics & p-value \\
\hline $\mathrm{H}_{1}$ & Website Quality $\rightarrow$ Purchase Intention & 0,418 & 5,547 & 0,000 \\
\hline $\mathrm{H}_{2}$ & Website Reputation $\rightarrow$ Purchase Intention & 0,298 & 3,750 & 0,000 \\
\hline $\mathrm{H}_{3}$ & Perceived Risk $\rightarrow$ Purchase Intention & 0,059 & 0,733 & 0,464 \\
\hline
\end{tabular}

Berdasarkan tabel di atas, dapat dilihat bahwa jalur variabel website quality memiliki pengaruh positif signifikan terhadap variabel purchase intention dengan nilai path coefficient sebesar 0,418 dan $p$-value sebesar 0,000. Variabel website quality juga merupakan prediktor terbesar terhadap 
variable purchase intention dengan nilai sebesar 0,418 . Hal ini berarti bahwa variabel website quality memberikan kontribusi terbesar terhadap perubahan naik turunnya variabel purchase intention. Sementara itu jalur variabel website reputation juga memiliki pengaruh positif signifikan terhadap variabel purchase intention dengan nilai path coefficient sebesar 0,298 dan $p$ value sebesar 0,000 dan merupakan prediktor terbesar kedua terhadap variabel purchase intention. Terakhir, jalur variabel perceived risk memiliki pengaruh positif tidak signifikan terhadap variabel purchase intention dengan nilai path coefficient sebesar 0,059 dan p-value sebesar 0,445 sehingga tidak dapat menjadi prediktor terhadap perubahan naik turunnya variabel purchase intention karena nilai path coefficient yang mendekati 0.

Hasil penelitian ini menunjukkan bahwa website quality memiliki pengaruh positif terhadap purchase intention sehingga $\mathrm{H}_{1}$ tidak ditolak. Hasil penelitian ini didukung oleh hasil penelitian yang dilakukan oleh Kim dan Lennon (2013); Law dan Bai (2008) dan Hsu, Chang dan Chen (2012) yang menemukan bahwa website quality memiliki pengaruh yang positif dengan purchase intention. Berdasarkan hasil temuan ini dapat disimpulkan bahwa website yang didesain dengan baik secara visual sehingga memudahkan pengguna untuk menavigasikan website tersebut, akan meningkatkan probabilitas pengguna untuk berbelanja pada website tersebut. Selain itu kecepatan dan kemudahan proses transaksi juga akan meningkatkan minat pengguna untuk melakukan pembelian. Website yang berkualitas juga dapat diartikan sebagai website yang dapat berfungsi dengan baik. Pengunjung yang merasa nyaman dalam menggunakan sebuah website akan cenderung untuk melakukan pembelian pada website tersebut.

Hipotesis kedua penelitian ini adalah adanya pengaruh yang positif antara website reputation dengan purchase intention. Hasil pengujian hipotesis menunjukkan bahwa $\mathrm{H}_{2}$ tidak ditolak. Hasil-hasil penelitian Kim dan Lennon (2013); Kim, Kim dan Yang (2013) dan Tangmanee dan Rawsena (2016) juga menunjukkan adanya pengaruh yang positif antara website reputation dengan purchase intention. Website dari perusahaan yang besar dan dikenal oleh banyak orang akan membentuk persepsi yang positif sehingga konsumen yang mengunjungi website tersebut akan merasa nyaman untuk berbelanja. Salah satu usaha yang dilakukan perusahaan untuk mendapatkan reputasi dan citra yang baik di mata konsumen adalah dengan melakukan promosi yang intensif dan berkesinambungan. Reputasi dan citra perusahaan yang baik akan memberikan rasa percaya kepada konsumen untuk mau berbelanja pada website tersebut karena konsumen percaya dengan promosi-promosi yang disampaikan oleh perusahaan. Selain itu, website dengan reputasi yang baik juga akan membuat pengguna merasa nyaman dan familiar pada saat mengunjungi website yang pada akhirnya akan dapat meningkatkan minat untuk berbelanja.

Hipotesis terakhir penelitian ini memprediksi pengaruh yang negatif antara perceived risk dengan purchase intention, sedangkan hasil uji path coefficient menunjukkan bahwa perceived risk memiliki pengaruh positif terhadap purchase intention sehingga $\mathrm{H}_{3}$ ditolak. Hal ini berbeda dengan hasil penelitian yang dilakukan oleh Li, Kim dan Park (2007) yang didukung oleh temuan pada penelitian Tangmanee dan Rawsena (2016) dan Ariffin, Mohan dan Goh (2018), bahwa perceived risk berpengaruh negatif terhadap purchase intention. Perbedaan hasil penelitian ini dengan penelitian-penelitian terdahulu tersebut dapat disebabkan karena responden yang mengunjungi website/aplikasi e-commerce dalam penelitian ini tidak merasa khawatir dengan keamanan website/aplikasi e-commerce tersebut, karena sistem sekuriti berlapis yang diterapkan membuat konsumen yakin bahwa website/aplikasi tersebut akan sulit untuk diretas oleh hacker. Sistem sekuriti yang diterapkan oleh website/aplikasi e-commerce tersebut antara lain verifikasi alamat email dan nomor HP, pengiriman kode OTP dan PIN serta verifikasi alat 
pembayaran. Namun demikian, kekhawatiran responden terhadap kualitas produk yang dijual pada website/aplikasi e-commerce tersebut dan proses pengiriman yang baik terbilang cukup tinggi. Hal ini kemungkinan disebabkan oleh kebijakan masing-masing toko penjual dan kurir pengantar yang tidak terafiliasi secara langsung dengan perusahaan e-commerce tersebut, meskipun konsumen dapat mengajukan komplain kepada customer service jika terjadi hal-hal yang tidak sesuai dengan harapan konsumen. Sementara itu kekhawatiran akan keamanan dan kerahasiaan data tetap ada karena kecurangan atau pembobolan yang dapat terjadi mungkin saja disebabkan oleh perusahaan e-commerce itu sendiri ataupun pihak eksternal dari perusahaan, seperti hacker ataupun pelaku social engineering.

\section{KESIMPULAN DAN SARAN}

Hasil penelitian ini menunjukkan bahwa website quality dan website reputation memiliki pengaruh yang positif signifikan terhadap purchase intention. Sementara itu perceived risk memiliki pengaruh positif tidak signifikan terhadap purchasen intention. Hasil penelitian ini juga menunjukkan bahwa website quality dan website reputation, secara berurutan, merupakan prediktor terbesar terhadap perubahan naik turunnya purchase intention, sedangkan perceived risk tidak dapat memprediksi perubahan pada purchase intention.

Implikasi manajerial dari penelitian ini terhadap perusahaan e-commerce secara umum adalah agar perusahaan dapat mempertahankan dan meningkatkan kualitas website. Salah satu indikator sebuah website yang baik menurut penelitian ini adalah proses transaksi yang mudah dan cepat. Hal ini dapat dilihat dari jumlah komplain yang diterima yang berkaitan dengan processing pada website. Selain itu, sebuah website yang baik harus mudah untuk digunakan dan diakses secara visual. Kebingungan pengunjung dalam menentukan atau memilih menu-menu yang harus dituju untuk mencapai suatu layanan atau produk tertentu menunjukkan bahwa website tersebut tidak berkualitas. Selanjutnya perusahaan agar tetap terus menjalin komunikasi yang baik dengan konsumen, yang salah satunya melalui promosi untuk membangun citra perusahaan yang baik; sebagaimana disebutkan dalam indikator variabel website reputation. Lebih lanjut, perusahaan disarankan untuk melakukan pembaruan website/aplikasi secara berkala untuk menjamin keamanan pengguna, yang meliputi kerahasiaan data pribadi dan/atau data kartu kredit/debit/rekening pengguna. Selain itu edukasi kepada pengguna untuk selalu merahasiakan data-data pribadi termasuk data kartu kredit/debit/rekening memainkan peran yang sangat penting dalam menjaga keamanan transaksi guna meminimalisasi potensi risiko pembobolan oleh hacker ataupun melalui social engineering. Terakhir, perusahaan disarankan untuk menerapkan standard operating procedure yang tegas terhadap toko-toko dan perusahaan ekspedisi yang menjadi rekanan atau mitra perusahaan. Salah satunya adalah dengan memberikan sanksi terhadap mitra-mitra yang tidak mematuhi standard operating procedure yang telah ditetapkan dan disepakati bersama. Dengan penerapan peraturan yang tegas tersebut, mulai dari informasi produk yang jelas dan transparan hingga proses pengiriman barang yang baik hingga sampai ke tujuan, akan dapat meminimalisasi kekhawatiran pengguna yang mungkin muncul pada saat akan berbelanja.

Berikut adalah saran-saran yang bagi peneliti berikutnya. Mayoritas responden penelitian ini adalah karyawan kantoran berusia 25-35 tahun dengan pendidikan terakhir setara S1. Hasil penelitian mungkin saja akan menunjukkan fakta yang berbeda dengan penelitian ini jika mayoritas responden memiliki karakteristik yang berbeda, seperti mahasiswa undergraduate dan/atau pelajar dengan usia di bawah 25 tahun ataupun ibu rumah tangga. Peneliti selanjutnya dapat mengkombinasikan variabel-variabel yang digunakan dalam penelitian ini dengan variabel-variabel lainnya yang mempengaruhi purchase intention, dengan atau tanpa adanya 
variabel mediasi; atau menggunakan variabel-variabel yang sama dengan yang penelitian ini namun menggunakan perusahaan non e-commerce sebagai subjek penelitian. Terakhir, peneliti selanjutnya dapat menggunakan jumlah sampel penelitian yang lebih besar untuk meningkatkan validitas hasil penelitian.

\section{Ucapan Terima Kasih}

Peneliti mengucapkan terima kasih kepada Lembaga Penelitian dan Pengabdian kepada Masyarakat Universitas Tarumanagara yang telah mendanai penelitian ini serta kepada pihakpihak yang telah membantu dalam pelaksanaan penelitian ini, mulai dari awal hingga selesai, khususnya pada pihak-pihak yang telah membantu proses pengumpulan data dan yang telah memberikan dukungan, saran dan motivasi kepada Penulis.

\section{REFERENSI}

Ariffin, Shaizatulaqma Kamalul, Mohan, Thenmoli \& Goh, Yen-Nee. (2018). Influence of consumers' perceived risk on consumers' online purchase intention. Journal of Research in Interactive Marketing, 12(3), 309-327.

Athapaththu, Jayani Chamarika and Kulathunga, D. (2018). Factors affecting online purchase intention: Effects of technology and social commerce. Internation Business Research, 11(10).

Australian Trade and Investment Commission (Austrade). (2018). e-Commerce in Indonesia. A guide for Australian Business. Retrieved Retrieved June 5, 2019, from https://www.thinkwithgoogle.com/intl/en-apac/tools-resources/research-studies/economy-sea-2018-southeast-asias-internet-economy-hits-inflection-point/.

Bonera, Michelle. (2011). The propensity of e-commerce usage: The influencing variables. Management Research Review, 34(7), 821-837.

CNBC Indonesia. (2019). Penjualan Tokopedia Cs Tembus Rp 133,5T , Kenapa Masih Rugi? Retrieved September 10, 2019, from https://www.cnbcindonesia.com/tech/20190304135922-37-58753/penjualan-tokopediacs-tembus-rp-1335-t-kenapa-masih-rugi.

Dowling, Grahame and Staelin, Richard. (1994). A model of perceived risk and intended riskhandling activity. Journal of Consumer Research, 21(1), 119-134.

Ganguly, Boudhayan, Dash, Satya Bhusan, Cyr, Dianne \& Head, Milena. (2010). The effects of website design on purchase intention in online shopping: The mediating role of trust and the moderating role of culture. International Journal of Electronic Business, 8(4/5).

Google Temasek. (2018). e-Conomy SEA 2018. Southeast Asia's internet economy hits an inflection point. Retrieved June 5, 2019, from https://www.thinkwithgoogle.com/intl/enapac/tools-resources/research-studies/e-conomy-sea-2018-southeast-asias-interneteconomy-hits-inflection-point/.

Hair Jr, Joe F., Hopkins, Lucas, Kuppelwieser, Volker G. \& Sarstedt, Marko. (2014). Partial least squares structural equation modeling (PLS-SEM). An emerging tool in business research. European Business Review, 26(2), 106-121.

Hsu, Chia-Lin, Chang, Kuo-Chien \& Chen, Mu-Chen. (2012). The impact of website quality on customer satisfaction and purchase intention: Perceived playfulness and perceived flow as mediators. Information System e-Business Management, 10, 549-570.

Jarvenpaa, Srikka L. and Tractinsky, Noam. (1999). Consumer trust in an internet store: A crosscultural validation, $J C M C, 5(2), 1-33$.

Kata Data. (2018). 2022, Penjualan e-commerce Indonesia mencapai US\$ 16 miliar. Retrieved June 5, 2019, from https://databoks.katadata.co.id/datapublish/2018/02/12/2022penjualan-e-commerce-indonesia-mencapai-rp-16-miliar. 
Kim, Jiyoung and Lennon, Sharron J. (2013). Effects of reputation and website quality on online consumers' emotion, perceived risk and purchase intention. Journal of Research in Interactive Marketing, 7(1), 33-56.

Kim, Jiyoung, Kim, Bu Yong \& Yang, Kiseol. (2013). Online retailer reputation and consumer response: Examining cross cultural differences. International Journal of Retail \& Distribution Management, 41(9), 688-705.

Kotler, Philip and Armstrong, Gary. (2012). Principles of Marketing (14th ed.). New Jersey, USA: Pearson Prentice Hall.

Kuncoro, Mudrajad. (2013). Metode Riset untuk Bisnis \& Ekonomi. Bagaimana Meneliti dan Menulis Tesis? (4th ed.). Jakarta, Indonesia: Penerbit Erlangga.

Kwahk, Kee-Young, Ge, Xi \& Park, Jun-Hyung. (2012). Investigating the determinants of purchase intention in $\mathrm{C} 2 \mathrm{C}$ e-commerce. International Journal of Economics and Management Engineering, 6(9).

Law, Rob and Bai, Billy. (2008). How do the preferences of online buyers and browers differ on the design and content of travel websites?. International Journal of Contemporary Hospitality Management, 20(4), 388-400.

Lee, Hao Suan Samuel, Khong, Kok Wei \& Hong, Jer Lang. (2014). Influence of online shopping enjoyment and trust towards purchase intention in social commerce sites. Handbook on the Emerging Trends in Scientific Research.

Li, Rong, Kim, JaeJon \& Park, JaeSung. (2007). The effects of internet shoppers' trust on their purchasing intention in China. Journal of Information Systems and Technology Management, 4(3), 269-286.

Lowry, Paul Benjamin, Vance, Anthony, Moody, Greg, Beckman, Bryan \& Read, Aaron. (2008). Explaining and predicting the Impact of branding alliances and web site quality on initial consumer trust of e-commerce web sites. Journal of Management Information Systems, 24(4), 201-227.

Lu, Ming Te and Yeung, Wing Lok. (1998). A framework for effective commercial web application development. Internet Research Electronic Networking Applications and Policy, 8(2).

Mirabi, Vahidreza, Akbariyeh, Hamid, \& Tahmasebifard, Hamid. (2015). A study of factors affecting on customers purchase intention. Case study: The agencies of Bono brand tile in Tehran. Journal of Multidisciplinary Engineering Science and Technology, 2(1), 267273.

Nuraini, Anisa. (2018). Indonesia initiatives in measuring e-commerce. Paper presented at the High Level Seminar on The Digital Economy: A Policy and Statistical Perspective, Beijing.

Sari, Melinda Ika and Keni, Keni. (2019). Pengaruh information quality dan relationship quality terhadap uncertainty reduction dan purchase intention. Jurnal Muara Ilmu Ekonomi dan Bisnis, 3(1),112-121.

Tangmanee, Chatpong and Rawsena, Chayanin. (2016). Direct and indirect effects of perceived risk and website reputation on purchase intention: A mediating role of online trust. International Journal of Research in Business and Social Science, 5(6), 1-11.

van der Heijden, Hans, Verhagen, Tibert \& Creemers, Marcel. (2003). Understanding online purchase intentions: Contributions from technology and trust perspectives. European Journal of Information System, 12, 41-48.

Weisberg, Jacob, Te'eni, Dov \& Arman, Limor. (2011). Past purchase and intention to purchase in e-commerce. The mediation of social presence and trust. Internet Research, 21(1), 8296. 
Wilson, Nicholas, Keni, Keni \& Tan, Pauline Henriette Pattyranie. (2019). The effect of website design quality on repurchase intention in the e-commerce industry: A cross-continental analysis. Gadjah Mada International Journal of Business, 21(2), 187-222.

Wu, Wann-Yih, Lee, Chia-Ling, Fu, Chen-Su \& Wang, Hong-Chun. (2014). How can online store layout design and atmosphere influence consumer shopping intention on a website. International Journal of Retail and Distribution Management, 42(1), 4-24. 